\title{
ATOS MENTAIS E COGNIÇÃO EM J. DUNS SCOTUS: UM ESTUDO DE CASO DO QUODL. XIII
}

Mental-acts and cognition in J. Duns scotus: a case study of QUODl. XIII

\author{
Guido José Rey Alt*
}

Resumo: O ensaio examina a ontologia de atos mentais desenvolvida por Scotus em Quodlibet XIII, dando atenção aos aspectos da filosofia da mente posteriores e presentes em Guilherme de Ockham. O tratamento tem ênfase na interpretação dos assim chamados modelos de 'existência objetiva' e de 'atos mentais' com respeito ao conteúdo mental e sua relação com a epistemologia da cognição.

Palavras-chave: Duns Scotus, Guilherme de Ockham, Ceticismo, Filosofia da mente.

\begin{abstract}
This essay examines Scotus's ontology of mental acts from his Quodlibet XIII, paying due attention to later aspects of the philosophy of mind to be found in William of Ockham. This treatment emphasizes the so called 'objective existence' and 'mental-act' theories of mental content and its relationship to the epistemology of cognition.
\end{abstract}

Keywords: Duns Scotus, William of Ockham, Skepticism, Philosophy of mind.

* Mestrando em Filosofia pela Pontifícia Universidade Católica do Rio Grande do Sul - PUCRS. Bolsista CNPq. Email: guido.alt@acad.pucrs.br

\begin{tabular}{|c|c|l|l|c|c|}
\hline intuitio & $\begin{array}{c}\text { ISSN } \\
1983-4012\end{array}$ & Porto Alegre & Vol.10 $-\mathrm{N}^{\circ} .2$ & $\begin{array}{c}\text { Dezembro } \\
2017\end{array}$ & p. 157-166 \\
\hline
\end{tabular}


Embora a cognição intuitiva tenha sido amplamente estudada na teoria do conhecimento de J. Duns Scotus, cremos ainda haver temas importantes da ontologia dos atos mentais, a qual é tema do Quodlibet XIII, ainda em aberto na pesquisa scotista. Tampouco ainda é clara, na medida em que pressupõe uma investigação em minúcia, a relação deste texto com a teoria do conhecimento de Guilherme de Ockham. Ganhar um tal entendimento pode ser relevante por diversas razões de aprofundamento histórico da compreensão em questões pertinentes e interseccionais de teoria do conhecimento e de filosofia da mente. As perguntas filosóficas de fundo que conduzem à presente inquirição, bem como a tentativa de abordar o texto scotista, são formuladas provisoriamente do seguinte modo:

i) na medida em que percepções dos próprios atos mentais são assumidas ineludíveis com respeito ao conteúdo, então o que, em dado estado ou ato, define um estado de coisas satisfazendo as mesmas condições? Ou seja, qual é a natureza de atos mentais?

ii) em contrapartida, quais são as implicações da assunção de uma teoria internalista de atos mentais para o processo de cognição que denominamos de contato direto com a realidade?

Cabe apontar que estes dois lados da teoria da cognição, a cognição dos próprios atos mentais e do mundo externo, não é perseguida em detalhe no que se segue, mas apenas serve de orientação filosófica para o estudo interpretativo. Objetivo do presente estudo é abordar, preliminarmente e em teor historiográfico, o influxo da ontologia scotista de atos mentais para a história do ceticismo na filosofia medieval, através, sobretudo, de consequências sobre a discussão sobre o ceticismo no racionalismo ockhamiano. O debate sobre as motivações, bem como as consequências céticas, de teorias do conhecimento da idade média, estende-se por longa data entre eruditos e historiadores da filosofia ${ }^{1}$. Pelo menos, o que se entendia por ceticismo na antiguidade clássica e tardia não é transmitido significativamente para o medievo até o século $14^{2}$. Ademais, entre os 'tropoi', os argumentos conducentes ao ceticismo de Diógenes Laércio na antiguidade tardia, nenhum destes corresponde a

\footnotetext{
${ }^{1}$ Uma visão geral oferece Perler, 2006, pp. 1-15.

2 Annas, J.; Barnes, J. (1985). Em todo caso, no ceticismo antigo, a percepção era apenas um dos 'tropoi' conducentes ao ceticismo, entre os quais se encontravam argumentos de natureza moral como o relativismo. Em todo caso, o ceticismo tardoantigo era conhecido para os medievais, e referido, por remissão a Cícero e através do Contra Academicos de Agostinho, como a visão dos academici.
}

\begin{tabular}{|c|c|c|c|c|c|}
\hline intuitio & $\begin{array}{c}\text { ISSN } \\
1983-4012\end{array}$ & Porto Alegre & Vol.10- $\mathrm{N}^{\circ} .2$ & $\begin{array}{c}\text { Dezembro } \\
2017\end{array}$ & p. 157-166 \\
\hline
\end{tabular}


qualquer tese de natureza teológica, como a doutrina da onipotência o parece originalmente fazer no ceticismo medieval em teoria do conhecimento.

No presente ensaio, busca-se apenas dar uma forma inicial à inquirição filosófica desta problemática por meio de estudos históricos e secundários. Dentro deste objetivo amplo, o ensaio propõe uma defesa preliminar da seguinte tese: uma argumentação da ontologia ockhamiana corretamente identificada por Marilyn M. Adams, a saber, a rejeição de uma 'teoria da existência objetiva' em favor da 'teoria dos atos mentais', encontra alguns elementos de antecipação no Quodlibet XIII de Scotus, em especial, na ontologia absoluta dos atos e operações mentais que Scotus desenvolve. Embora o influxo desta ontologia dos atos mentais sobre o ceticismo seja o pano de fundo de sugestão e pesquisa, não se aborda diretamente esta conexão, mas se busca apenas aventar um passo intermediário para o objetivo de iniciar apontamentos de compreensão desta conexão, a serem perseguidos ainda na pesquisa.

\section{I}

No estado da arte acerca da epistemologia medieval, o aspecto que destaca a teoria do conhecimento dos medievais dos séculos XIII e XIV é o seu foco na cognição. Não é apenas um acidente terminológico que ela seja um tema precípuo na consciência teórica dos medievais. A riqueza do vocabulário introspectivo para atos mentais, centralmente, para a vontade, na filosofia medieval, é classicamente apontada em acepção comparativa com o mundo intelectual grego ${ }^{3}$, e o mesmo parece valer para a teoria do conhecimento. Talvez tenha sido uma inovação na teoria do conhecimento deste período latino a formulação clara de uma teoria da cognição com base neste vocabulário. A teoria da cognição dupla é a chave medieval para entender um desdobramento desse processo na história intelectual e filosófica das ideias sobre a teoria do conhecimento no Ocidente.

A formulação originária e rica em influxo histórico-intelectual de dois tipos fundamentais de cognição ou de atos mentais, quais sejam, a cognição abstrativa e a intuitiva, ocorre exatamente no prólogo ao Ordinatio de J. Duns Scotus. A assim conhecida 'teoria da dupla cognição', e a sua distinção paralela entre cognição abstrativa e a intuitiva ${ }^{4}$, pode ser entendida como uma compreensiva abordagem da consciência perceptual e dos mecanismos de geração do conhecimento a sua base e, assim, uma

\footnotetext{
${ }^{3}$ Por exemplo, como é tese corrente sobre a teoria da vontade desde A. Dihle (1982).

4 “(...) primam intellectionem seu cognitionem voco 'abstractivam', quae est ipsius quidditatis, secundum quod abstrahit ab acuali existentia et non-existentia. Secundam, scilicet quae est quiditatis rei secundum eius existentiam actualem (vel quae est rei praesentis secundum talen existentiam), voco 'intellectionem intuitivam'. (...) (Ord. II d.3 p. 2 q.2). Ambas as cognições correspondem, prima facie, a atos apreensivos, que acompanham atos adjudicativos (cf. Tachau, K., 1981, p. 22).
}

\begin{tabular}{|c|c|c|c|c|c|}
\hline intuitio & $\begin{array}{c}\text { ISSN } \\
1983-4012\end{array}$ & Porto Alegre & Vol.10- $\mathrm{N}^{\circ} .2$ & $\begin{array}{c}\text { Dezembro } \\
2017\end{array}$ & p. 157-166 \\
\hline
\end{tabular}


abordagem sobre a natureza da percepção que antecede questões epistemológica em aceitação estrita ${ }^{5}$. Os problemas interpretativos mais interessantes da teoria da cognição dupla, não tanto devido a suas assunções mais complexas na teoria de conteúdo ou de objeto mental, mas sim devido as alegações de conhecimento a modo de realismo direto feitas por base nela, certamente pendem para a cognitio intuitiva. Na formulação original de Scotus, as cláusulas de especificação deste desempenho da razão e das suas condições são assemelhadas a assunções do realismo direto com respeito percepção: à razão é dado a conhecer, por meio da cognição intuitiva, o objeto enquanto 'presente e existente' (ut praesens et existens). A teoria da cognição intuitiva parece, largamente, ser uma abordagem da percepção e uma elucidação do conhecimento a sua base a modo de acquaintance ${ }^{6}$. Dentro destas condições, portanto, está incluído o 'contato direto' com o mundo, que torna uma função do conceito de cognição intuitiva, fundamentalmente, o de descrever e classificar atos verídicos de percepção.

Tanto para Scotus, quanto também para Ockham, portanto, a cognição intuitiva é o mecanismo de geração da consciência perceptual; ela fornece evidência para a existência de conteúdos apreendidos perceptualmente de modo imediato, o seja, explica a evidência para juízos sobre conteúdos contingentes. Para ambos, brevemente dito, cognição intuitiva é toda apreensão de verdades contingentes nãocomplexas, a qual, ademais e a princípio, não seria mediada por qualquer species ${ }^{7}$. Abordagem feita deste desempenho da razão, porém, que é feita por Guilherme de Ockham, ou seja, do processo cognitivo sob a rubrica da cognição intuitiva, tem uma remissão e uma recolocação da problemática epistemológica que ela adquirira para Scotus. Afinal de contas, Ockham não aceita todas mesmas condições de sucedimento da cognição intuitiva que Scotus.

A diferença da acepção ockhamiana para a scotista é clara na definição das condições de sucedimento da cognição intuitiva. Enquanto que, para Scotus, a cláusula 'ut praesens et existens' sinaliza uma condição necessária para o processo cognitivo, não é claro que este seja o caso para Ockham. De fato, parece que a sua definição inclui casos (não naturais) onde a cognição intuitiva ao menos não é incompatível com a não-existência dos seus conteúdos, em duas passagens do prólogo ao Ordinatio ockhamiano (tradução nossa):

A cognição intuitiva de algo [res] é aquela cognição tal que, em virtude dela, pode ser sabido se algo [res] é ou não é, de tal como que se algo é, o intelecto imediamente adjudica o seu ser e conhece evidentemente o seu ser, a não ser que seja eventualmente impedido pela imperfeição daquela cognição ... (Ord. prol. q.1 [OT: 26-27; 31])

\footnotetext{
${ }^{5}$ Em poucos casos de temáticas em teoria do conhecimento e da cognição medieval que se encaixe perfeitamente sob o rótulo 'epistemologia', enquanto tratamento unificado e especializado do conhecimento, como na disciplina filosófica contemporânea.

${ }^{6}$ Possivelmente esta teoria se desenvolve, em Scotus, como reação anticética a motivações de Henrique de Gand sobre o processo cognitivo que ele denomina por 'cognitio veritatis', em oposição a 'cognitio veri', que se originam da tradição cética de acepção neoplatônica. Cf. Perler, 2004, pp. 187-190.

${ }^{7}$ Tachau, K., Op. cit., pp.104-105. As fontes ockhamianas principais são Reportatio II, q.15; Ordinatio, Prol. q.1.
}

\begin{tabular}{|c|c|c|c|c|c|}
\hline intuitio & $\begin{array}{c}\text { ISSN } \\
1983-4012\end{array}$ & Porto Alegre & Vol.10- N.2 & $\begin{array}{c}\text { Dezembro } \\
2017\end{array}$ & p. 157-166 \\
\hline
\end{tabular}


Quanto ao segundo argumento: não é inconsistente que algo seja intuitivamente visto e, portanto, que o intelecto creia que algo não é muito embora isto não possa ser o caso naturalmente (Ord. prol. q.1 [OT: 16-72] $)^{8}$.

Para Ockham, pois, na passagem supracitada, um discurso sobre a 'visão intuitiva, de que a coisa não é', é uma forma aceitável de falar sobre o tipo de relação que constitui a cognição intuitiva, o que é surpreendente. Por se tratar claramente de uma relação do ato mental para com conteúdos não-existentes, quando, na acepção scotista, os atos mentais de cognição intuitiva aparentam ser atos exclusivamente verídicos ${ }^{9}$. Contudo, adiciona-se, na passagem supracitada, que este não é um desempenho natural da razão (quamvis naturaliter non possit hoc fieri). Portanto, tem-se a tese ockhamiana sobre a cognição intuitiva que, de um lado, transgride a cláusula da presença e existência e, de outro, as condições independentes do 'conhecimento natural' e sua possibilidade a razão humana, ambas posições claramente scotistas. Apesar da expressão para tal ato mental ser um oximoro, caso leve-se a sério a tese ockhamiana sobre a cognição intuitiva, não é difícil eruir quais sejam as consequências céticas da linha de argumentação, que pode ser uma nova via para o ceticismo, e para o discurso cético na teoria do conhecimento medieval em geral.

A tese ockhamiana da cognição intuitiva de não-existentes é vinculada, em sua formulação teórica, ao princípio de onipotência ${ }^{10}$. Neste contexto, a discussão da possibilidade de manter-se em existência uma cognição por poder divino, embora os seus termos (o sujeito e o objeto da cognição, ou seja, os termos da adscrição epistêmica "S sabe que $p$ ") não estejam mais participando do mesmo. $\mathrm{O}$ paradoxo tange a 'causa de conservação' de atos mentais, a saber, da conservação do ato no caso da 'destruição' termos na discussão teológica de caso do experimento mental da 'cognição de nãoexistentes ${ }^{\prime 11}$. Contudo, ela apresenta importantes considerações na virada para uma teoria de objetos na ontologia. Esta mudança de perspectiva foi identificada por Marilyn Adams (1997). Para ela, a consideração ockhamiana dos objetos de atos apreensivos e do seu modo de existência passou por uma virada entre textos. Uma primeira consideração seria a 'teoria da existência objetiva', a qual fora seguida pela 'teoria dos atos mentais'.

\footnotetext{
${ }^{8}$ Notitia intuitiva rei est talis notitia virtute cuius potest sciri utrum res sit vel non, ita quod si res sit, statim intellectus iudicat eam esse et evidenter cognoscit eam esse, nisi forte impediatur propter imperfectionem illius notitiae (...) (Ord. Prol. q.1 [OT: 26-27; 31]. Ad secundum: forte non est inconveniens quod res intuitive videatur et tamen quod intellectus ille credat rem non esse, quamvis naturaliter non possit hoc fieri (Ord. prol. q.1 [OT: 16-72].

${ }^{9}$ Guillherme de Ockham, Prólogo às Sentenças, Questão $1^{\text {a }}$ (tradução Antônio dos Santos), p. 84.

${ }^{10}$ Guilherme de Ockham (tradução Antônio dos Santos), Op. cit., p.86

${ }^{11}$ Um exemplo particularmente feliz é o da visão de uma estrela distante da terra: "Assim como, se vejo intuitivamente uma estrela existente no céu, esta visão intuitiva, quer seja sensitiva ou intelectiva, é disitinta, quanto ao lugar e ao sujeito, do objeto visto; logo, esta visão pode permanecer estando a estrela destruída; logo, etc" (Guilherme de Ockham, Op. cit., pp.86-7)
}

\begin{tabular}{|c|c|l|l|c|c|}
\hline intuitio & $\begin{array}{c}\text { ISSN } \\
1983-4012\end{array}$ & Porto Alegre & Vol.10- No.2 & $\begin{array}{c}\text { Dezembro } \\
2017\end{array}$ & p. 157-166 \\
\hline
\end{tabular}


A noção ockhamiana da cognição intuitiva como mecanismo de evidência dos juízos sobre nãoexistentes gerou interesse entre intérpretes ${ }^{12}$. As posições de Ockham podem ser lidas da seguinte maneira. Cognições, em geral, são apreensões de conteúdo $^{13}$. O que dizer geralmente, porém, do modo de existência dos objetos que existem para cognições? Ockham defendera o princípio que objetos do pensamento têm ou um modo real, ou modo 'não-real', objetivo, de existência. Contudo, segundo a apresentação de Adams, Ockham teria antevisto diversos problemas na 'teoria do existente objetivo' em seus escritos tardios, em especial, na Summa Logicae ${ }^{14}$.

Ockham segue a prática dos medievais de pensar o estatuto ontológico de percepções nãoverídicas em discussão da natureza de conteúdos mentais. É em interlocução com Pedro de Aureoli que Ockham antecipa suas objeções a teoria da existência objetiva, propondo, então, uma teoria própria de atos mentais epistemologicamente motivada. Aureoli postula o modo de 'existência aparente' (esse apparens) para objetos de percepções não-verídicas, ou seja, em especial, na discussão de casos de ilusão sensória. Adams (1977, p.157) interpreta este princípio da seguinte maneira:

P1: Se $x$ parece ser $F$, $G$, etc., então esta instância de $F$-idade, G-idade, etc., deve existir (em algum sentido).

Ockham parece, na refutação a teoria de Aureoli, colocar uma objeção a teóricos da existência objetiva baseada, em seu cerne, sobre uma consequência cética. A saber, toma-se P1, então a substituição legítima P2, o mesmo vale para a teoria de existência objetiva, a saber,

P2: Se $x$ parece ser $F, G$, etc., então esta instância de $F$-idade, G-idade, etc., tem existência objetiva.

\footnotetext{
${ }^{12}$ Entre os mesmos encontram-se, representativamente, E. Gilson (1937) e Ph. Boehner (1943), e recentemente uma apreciação crítica do debate sobre a cognição intuitiva de não existentes em relação ao ceticismo fora proposta por Karger, E., 1999.

${ }^{13}$ Esta premissa não se aplicaria, sem qualificações, à cognição intuitiva na posição scotista, nem a a importantes assunções ockhamianas de realismo direto. Contudo, uma parte importante da nossa vida cognitiva é a apreensão de conteúdos por meio de representações, o que ambos autores denominam de 'cognição abstrativa', a qual requer uma elucidação da intencionalidade de atos mentais.

${ }^{14}$ Uma objeção, baseada na liberdade do ato de criação, contudo, já se encontra na Ord. I d.43 q.2, referida explicitamente a teoria scotista do ser inteligível, uma vez que ele limitaria nomicamente as possibilidades de atos contingentes por parte da vontade divina Outras objeções, são análogas as objeções a 'prova ontológica' da existência de Deus feitas por Gaunillo a Anselmo (cf. Adams, M., 1977, p. 156; p. 169).
}

\begin{tabular}{|c|c|l|l|c|c|}
\hline intuitio & $\begin{array}{c}\text { ISSN } \\
1983-4012\end{array}$ & Porto Alegre & Vol.10- $\mathrm{N}^{\circ} .2$ & $\begin{array}{c}\text { Dezembro } \\
2017\end{array}$ & p. 157-166 \\
\hline
\end{tabular}


O discurso sobre objetos de ilusões da percepção sensória que lhes adscreve um modo de existência é familiar aos medievais, afinal de contas, ele é talhado para preservar o realismo direto na teoria da consciência perceptual, a posição favorecida pela grande de teorias do conhecimento no período $^{15}$. Contudo, Ockham aduz uma consequência paradoxal da teoria de Aureoli, qual seja, a distinção entre percepções verídicas e inverídicas é impossível sob assunção de P1 ou de P2, uma vez que ambos princípios cobrem atos verídicos e ilusórios da consciência perceptual (Adams, p. 158).

Com base nesta argumentação, portanto, Ockham quer mostrar que a teoria de existência objetiva é insuficiente quando aplicada a nossas cognições intuitivas e abstrativas de particulares e, por conseguinte, a substitui por uma teoria de atos mentais (Adams, Op. cit., p.163). Para a teoria de atos mentais, objetos de cognições são, tão somente, entidades atuais.

\section{II}

A tese que conteúdos mentais sejam qualidades da mente é encontrada, no texto da Quodl. 13, na teoria de Scotus sobre atos mentais. Trata-se de uma resposta à pergunta (i), feita no início do ensaio sobre a natureza de atos mentais: conteúdos ou conceitos são atributos, qualidades, que constituem o estado de coisas intencional. A mente, pois, existe no modo real, o que significa que os seus predicados principalmente, estados intencionais e epistêmicos - lhe são atribuídos sem a qualificação modal da existência 'não-real'"16; ou, na linguagem de Meinong, ela não apenas tem subsistência (Aussersein), mas tem existência, na medida em que é um acidente real ou uma existência subjetiva ${ }^{17}$. Em geral (mais claramente a partir de textos como Ord. d.3 p.3 q.1 n. 369), em diferença de Ockham, para Scotus, certos predicados da mente e, sobretudo, propriedades relacionais suas para com objetos, são um tipo de entidade que tem subsistência (se nos é permitido fazer o uso da expressão meinongiana) ${ }^{18}$, uma vez que ele não abandona completamente uma teoria de existência objetiva dos conteúdos mentais do seu discurso ontológico.

Nesta Quodlibet XIII ${ }^{19}$ trata-se, especialmente, ao lado da Quodl. VI, de uma fonte importante para a discussão scotista da cognitio intuitiva. A indagação ou questão correspondente quer saber se atos

\footnotetext{
${ }^{15}$ Adams, M., Op. cit., p. 161

${ }^{16}$ Para o tratamento da existência não-real como um operador modal, cf. Adams, Op. cit. p.159.

${ }^{17} \mathrm{Na}$ ontologia intensional (em oposição à extensional, devido à formalização da teoria ontológica a qual ela autoriza) de Alexius Meinong, objetos ou entidades podem ter dois 'modos de ser', quais sejam, a existência (Existenz) espacio-temporal ou a subsistência (Bestand). Cf. Jacquette (1996, p. 7).

${ }^{18}$ Adota-se aqui a terminologia entidade ao invés de objeto, para que o vocabulário psicológico não seja generalizado na ontologia. Há um debate sobre se a teoria de objetos de Meinong deixa-se caracterizar como uma teoria de entidades ou de objetos. Cf. Jacquette (1996).

${ }^{19}$ No que se segue, cita-se tradução não publicada feita a partir de esboços de aula completados pelo Prof. Dr. Roberto Hofmeister Pich.
}

\begin{tabular}{|c|c|l|l|c|c|}
\hline intuitio & $\begin{array}{c}\text { ISSN } \\
1983-4012\end{array}$ & Porto Alegre & Vol.10- $\mathrm{N}^{\circ} .2$ & $\begin{array}{c}\text { Dezembro } \\
2017\end{array}$ & p. 157-166 \\
\hline
\end{tabular}


mentais, abrangidos atos 'intelectuais' (cognoscendi) bem como 'apetitivos' (appetendi), devem pertencer à classe ontológica de entidades absolutas ou à classe de entidades relativas. Scotus segue, em linha de argumentação, uma premissa adotada por Ockham: atos mentais pertencem, em primeiro lugar, à categoria ontológica da qualidade, o que as empresta realidade independente.

Scotus distingue dois tipos de atos mentais: atos cognitivos terminados e atuais (cognitio actualis $)^{20}$. Aparentemente, cognições atuais são caracterizadas conforme um critério relacional distinto de atos terminados (i.e., atos que tem uma relação real com objetos anexa a si). Scotus caracteriza-as, mais precisamente, como operações mentais, e não como ações. Por operações, no texto, sugere-se uma noção bem específica sobre a realidade da mente que tem. Operações, em suma, não pertencem a uma categoria ontológica que porta uma relação (Quodl. XIII, I [5] 16), como a ação o faz.

Se estados mentais não pressupõem absolutamente relação com objetos, implica isso que a intencionalidade não é condição necessária de atos mentais ${ }^{21}$ ? Parece, antes bem, que a intencionalidade não seja uma condição suficiente do mental ${ }^{22}$. Cognições intuitivas e abstrativas têm em comum serem atos mentais de apreensão que apresentam termos para o ajuizamento. Vários estados e atos que pertencem à realidade da mente não têm o desempenho epistêmico de apreensões; quem sente dor, não tem dores de algo, mas dores são algo tido. Contudo, pode o mesmo também se aplicar àquele desempenho do pensamento ao qual normalmente associamos à intencionalidade, isto é, ao pensamento que se refere a objetos, como o fazem cognições? A pergunta é tanto relevante para a ontologia dos atos mentais, quanto para o problema do ceticismo na teoria do conhecimento, afinal, uma condição do pensamento intencional é, precisamente, que a sua referência seja constituída por um ato de percepção.

O modo como a intencionalidade se vincula a ontologia scotista dos atos mentais, especialmente, no quadro de sua determinação como operações - i.e., como entidades nas quais a relação requer uma explicação metafísica, haja vista não ser pressuposta analiticamente, i.e., não pertencer a uma categoria relacional -, na discussão da tese de que na operação há uma relação anexa (Quod. XIII, I [6] 17). A função de relações com objetos extrínsecos a realidade mental recebe, ao menos para a classe das apetições, um arrazoado teleológico da parte de Scotus, com referência a Aristóteles; a função de relações é conectar ou conjugar a criatura ao seu fim último, ou seja, esta é a sua razão formal (Quodl. XIII, II [6], 19).

\footnotetext{
20 "Essa questão não pergunta sobre o ato terminado quanto ao conhecimento tal como quanto ao termo, ato esse pelo qual, a saber, é produzido ou trazido ou induzido o próprio conhecimento, mas [a questão] pergunta sobre o ato de conhecer que é, a saber, o conhecimento atual" (Quodl. XII, [2] 4, Tradução nossa).

${ }^{21}$ Cabe o apontamento (devido a uma nota oportuna de um dos revisores do artigo), que no texto da Ord. I d.36 q. un, a relação é 'diminuente' do ser do ato mental, porém é um instante necessário da cognição (n.54). O texto do Quodlib. XII tem uma pergunta mais ampla e um escopo distinto de outros textos scotistas, de modo que é difícil de determinar se há contradição com teorias anteriores, ao menos no escopo limitado do presente artigo.

${ }^{22}$ No modo de falar de Scotus, operações têm, afinal, uma 'relação anexa a si' (no modo elíptico de expressão scotista), embora não pertençam, estritamente, a uma categoria ontológica relacional.
}

\begin{tabular}{|c|c|c|c|c|c|}
\hline intuitio & $\begin{array}{c}\text { ISSN } \\
1983-4012\end{array}$ & Porto Alegre & Vol.10 - No.2 & $\begin{array}{c}\text { Dezembro } \\
2017\end{array}$ & p. 157-166 \\
\hline
\end{tabular}


Com respeito, ademais, aos atos mentais de cognições, Scotus os discute em paralelo, os da cognição abstrativa e os da intuitiva. Para nosso propósito, é importante identificar, mesmo que preliminarmente e de modo tentativo, o seguinte elemento de contraste com a teoria de atos ockhamiana: em que medida a versão da teoria absoluta de atos mentais, na versão scotista, admite relações não-reais com objetos, isto é, relações subsistentes, e por qual motivo?

Na nossa hipótese, um dos motivos é que Scotus não abandona completamente uma teoria de existência objetiva dos conteúdos mentais neste Quodlibet (em que pese os pontos mencionados na nota 21), tampouco de uma relação com objetos no modo não-real de ser. Scotus adota a posição de que atos mentais são entidades absolutas, isto é, que os seus predicados se the atêm como qualidades e não, essencialmente, como relações. A razão parece ser que, para Scotus, em diferença de Ockham, nem todo conteúdo cognitivo é tal que os seus termos podem ser reduzidos a objetos atuais, como mostra a discussão do 'ser conhecido' (esse cognitum)

[a relação] de dependência do objeto enquanto conhecido para com o objeto enquanto aquilo pelo que é conhecido - é entre extremos não enquanto têm ser real, mas tão somente enquanto têm ser conhecido, essa relação é por isso mesmo não pura e simplesmente real (Quodl. XIII, II [12] 37, tradução nossa)

\section{Apontamentos Finais}

Como apontamentos da presente investigação parcial, temos que a ontologia scotista de atos mentais no Quodl. XIII tem elementos de antecipação da versão ockhamiana da cognição inutitiva, sobretudo, na classificação dos predicados da mente, i.e., atos e estados mentais, como qualidades ou acidentes reais. Claramente, ademais, a cognição de não-existentes, tal como discutida por Ockham, tem como premissa a tese de que atos mentais sejam entidades absolutas, o que se encontra na determinação scotista dos mesmos como operações, ou seja, atos que não são essencialmente relacionais.

Contudo, Scotus não abandona o modelo da teoria de existência objetiva dos conteúdos mentais. Por que esta classificação ontológica de atos mentais tem impacto sobre o entendimento epistemológico do processo de cognição? Em primeiro lugar, o texto do Quodlibet XIII, ao lado do Quodlibet VI, é um texto central para entender a posição scotista sobre a cognição intuitiva, contribuição central de Scotus para a teoria do conhecimento na idade média.

Na resposta de Scotus ao ceticismo, na Ordinatio I d.3, são defendidas fontes do conhecimento natural, contra a inspiração neoplatônica de Henrique de Gand. Entre estas fontes, se encontram verdades analíticas, compreensão de princípios naturais, e a certeza sobre os próprios atos mentais (Perler, 2004, pp. 196-198). Como resultado geral do exame da ontologia de atos mentais e suas implicações epistêmicas, ode-se aventar que a estratégia não reducionista quanto às modalidades epistêmicas, adotada na $\mathrm{Ord}$. I d.3,

\begin{tabular}{|c|c|l|l|c|c|}
\hline intuitio & $\begin{array}{c}\text { ISSN } \\
1983-4012\end{array}$ & Porto Alegre & Vol.10- No.2 & $\begin{array}{c}\text { Dezembro } \\
2017\end{array}$ & p. 157-166 \\
\hline
\end{tabular}


tenha a ver, precisamente, com preservar certeza de cognições dos próprios atos mentais ante às dificuldades, apresentadas às alegações epistêmicas com base na cognição, de uma ontologia de atos mentais como a de Quodl. XIII.

\section{Referências}

ANNAS, J.; BARNES, J. (orgs.). The Modes of Scepticism. Cambridge: University Press, 1985

ADAMS, M. M. Ockham's Nominalism and Unreal Entities. The Philosophical Review, vol. 86, n.2 (1977), pp. 144176.

BOEHNER, P. "The notitia intuitiva of non-existents according to William Ockham: with a critical study of the text of Ockham's 'Reportatio' and a revised edition of Rep. II, q. 14-15”. Traditio, Vol. 1, 1943, pp.223-275.

DUNS SCOTUS, I. Quaestiones Quodlibetales. ed. L. Wadding, vol. 12. Lyons: 1639. 1997- 2006 Opera philosophica. 5 vols. Ed. St. Bonaventure University. The Franciscan Institute,St. Bonaventure,

JACQUETTE, D. Meinongian Logic: The Semantics of Existence and Nonexistence. Berlin: Walter de Gruyter, 1996.

KARGER, E. “Ockham's Misunderstood Theory of Intuitive and Abstractive Cognition”. In: Spade, Paul V. (ed.) The Cambridge Companion to Ockham. Cambridge/New York: Cambridge University Press, 1999.

OCKHAM, W. Opera philosophica et theologica, Gedeon Gál, et al., ed. 17 vols. St. Bonaventure, N. Y.: The Franciscan Institute. 1967-88.

OCKHAM, G. Prólogo às Sentenças, Questão 1a. In: OCKHAM, Guilherme. (trad. Antônio Raimundo dos Santos). Repensando a Filosofia. Prólogo do Comentário de Ockham às Sentenças, Questão 1a. Porto Alegre: EDIPUCRS, 1997.

PERLER, D. Zweifel und Gewissheit. Skeptische Debatten im Mittelalter. Frankfurt am Main: Vittorio Klostermann, 2006

PERLER, D. Theorien der Intentionalität im Mittelalter. Frankfurt am Main: Vittorio Klostermann, 2004.

TACHAU, K. Vision and Certitude in the Age of Ockham. Michigan: University Microfilms International, 1981.

Recebido em: 15/09/2017

Aprovado para a publicação em: 03/11/2017

\begin{tabular}{|c|c|c|c|c|c|}
\hline intuitio & $\begin{array}{c}\text { ISSN } \\
1983-4012\end{array}$ & Porto Alegre & Vol.10- $\mathrm{N}^{\circ} .2$ & $\begin{array}{c}\text { Dezembro } \\
2017\end{array}$ & p. 157-166 \\
\hline
\end{tabular}

